\title{
Prevalence of low back pain and associated risk factors among professional car drivers in Dhaka city, Bangladesh
}

\author{
Begum Nurun Nahar ${ }^{1}$, G. U. Ahsan' ${ }^{2}$ Nazmul A. Khan ${ }^{3}$ \\ ${ }^{1}$ Senior Executive, Health-Shared Service Center, Grameenphone Ltd., Dhaka, Bangladesh. ${ }^{2}$ Chairman, ${ }^{3}$ Associate Professor, \\ Department of Public Health, North South University, Dhaka, Bangladesh.
}

\begin{abstract}
Low back pain (LBP) is common and affects most people at some point in their life. The exact cause of LBP among professional car drivers is still uncertain. Epidemiological studies of LBP have been performed among general populations and professional drivers in different countries; however the data on LBP in this professional category is scarce in Bangladesh. This paper investigates the prevalence of LBP among professional car drivers in Dhaka city and examines the relationship between back pain and years of driving, driving duration per day and the body weight of the drivers. A cross-sectional study was performed during December 2010 using a questionnaire and car drivers who experienced back pain for at least one day during the past 12 months were included in the study. The study demonstrated that $78 \%$ of car drivers reported LBP for at least one day during the past 12 months. The study also revealed age, daily and cumulative driving in drivers and stature are among the risk factors of LBP. Occupational health and safety management interventions should be implemented to prevent adverse health effects in professional car drivers.
\end{abstract}

Keywords: Lower Back pain, Professional car drivers, Risk factors, Driving duration, Bangladesh.

\section{Introduction}

Low back pain (LBP) is a common musculoskeletal complaint in all parts of the world. Epidemiological studies of LBP have been performed among general populations and professional drivers in different countries: $;{ }^{1-7}$ however the data on LBP in this professional category is scarce in Bangladesh. ${ }^{3}$ After headaches and tiredness, back pain is the third most common health problem reported by individuals. ${ }^{8}$ The exact cause of increased prevalence of LBP in populations of professional car drivers is often uncertain. The most frequently reported risk factor for LBP is heavy physical workload such as lifting, awkward posture, and whole body vibration. ${ }^{9-11}$ Lifestyle is also considered a risk factor of LBP. Smoking behavior, ${ }^{9,12,13}$ lack of physical exercise, ${ }^{9}$ and short sleep hours ${ }^{14}$ increase the risk of LBP. An association between LBP and psychosocial factors has also been reported..$^{9,15,16}$ The studies of professional drivers mostly considered drivers of trucks, tractors, buses and heavy machines. ${ }^{1-7}$ Professional car drivers in Dhaka city is a large professional community as most of the cars are driven by hired professional drivers. Normally they work under stress and drive for long hours. For different members of a single family the car used to ply on the road almost all day and drivers get very little rest. Also for taxi drivers they work long hours to earn more money. So, Dhaka city is a logical place to do the further study on LBP among professional car drivers. The aim of this paper was to determine the prevalence of LBP among professional car drivers in Dhaka city and to examine the relationship between back pain and years of

\section{Practice Points}

- Low back pain (LBP) is common and affects most people at some point in their life.

- The study estimated that $78 \%$ of professional car drivers suffer from LBP.

- It was also found that the key risk factors for car driver for LBP are long working hours, $\mathrm{BMI}$, and years of driving.

- Considering high risk of developing LBP for car drivers in Dhaka city, relevant interventions are recommended e.g. measures to reduce driving hours.

- Occupational health and safety management interventions should be implemented to prevent adverse health effects in professional car drivers.

driving, driving duration per day and the body weight of the drivers.

\section{Materials and methods}

The design of this study was a cross-sectional survey using a questionnaire to investigate the prevalence of LBP and to identify risk factors among a representative sample of car drivers in Dhaka City during December

Correspondence: Dr. Begum Nurun Nahar, Senior Executive, Health - Shared Service Center, Grameenphone Ltd., Dhaka, Bangladesh. E-mail: nurunnahar.diana@gmail.com. 
2010. A random sampling of car drivers was done using OpenEpi Version 2, ${ }^{17}$ considering an expected prevalence of $80 \%$, and using a confidence level of $95 \%$ the sample size for cross-sectional study was calculated as 246. Male drivers within age 25 to 65 who have driving history of at least 2 years were included in the study and those who had history of low back surgery or history of neurological problems were excluded.

The questionnaire had 14 questions having mainly binary or multiple choice answers and divided into the three sections. The first section included driver's personal details (e.g. age, gender and smoking habits), second section highlighted current job (i.e. driving per day, length of driving as an occupation etc.), and the last section included questions related to LBP history. A pilot study was conducted with a group of drivers to test the consistency of the questionnaire and time needed for the completion. The questionnaire required approximately 10 minutes to complete.

Interviews were conducted in parking places of big shopping mall, university, corporate office, residential apartment, hospital and few gas stations of Dhaka city. To collect 246 data the interviewer had to approach around 260 car drivers. There was no specific incentive in the form of money or gifts were offered to the respondents.

All the responses from the car drivers were entered and analyzed by using SPSS 17 . We calculated the 12 month prevalence, and binary logistic regression for estimating the 12 months odds ratio (OR) of having LBW.

\section{Results}

Table 1 presents some demographic characteristics of the study population. Among the 246 data collected 192 (78\%) respondents had experienced LBP within past 12 months which lasted for more than a day. Those who suffered from LBP, $83 \%$ of them had to take day-off and $80 \%$ reported persistent LBP during past one month. None of the respondents was owner of the car and none reported regular baggage handling either.

Table 2 summarizes the results of the binary logistic regression for estimating the 12 months odd ratio (OR) of having low back pain. The OR comparing driving more than 7 hour/day with driving 1-7 hour/day was a risk factor for LBW. Handling baggage and sleeping sometimes in the car seat during a rest break was not found to be risk factors for LBW. We did not find any statistically significant relationship between LBP and smoking habit.

BMI at 24 or above was a risk factor for LBW was identified when compared to the $15-23.99 \mathrm{~kg} / \mathrm{m}^{2}$ group. Analysis for car ownership could not be done as all collected data are for employed drivers. More years of driving car were positively related to LBP, i.e. the group working for 9-16 years had about four times higher probability of developing LBP than the group working for 2-8 years. Whereas those who are driving for more than 16 years had chance of LBP of about 10 times higher compared to those who drive for less than 8 years. Age was also related to pain prevalence. Prevalence of LBP was 4.67 times higher for drivers aged more than 40 years compared to drivers of age 25-40 years.

Table 1: Demographic characteristics of the study population

\begin{tabular}{|l|c|c|}
\hline \multicolumn{1}{|c|}{ Factors } & Respondents $^{\mathrm{a}}$ & Range $^{\mathrm{b}}$ \\
\hline Age (years) & $42.60 \pm 12.34$ & $25-65$ \\
\hline Smoking habit & & \\
\hline Never & $50 \pm 20.3$ & \\
\hline Sometimes & $58+23.6$ & \\
\hline Frequently & $36+14.6$ & \\
\hline Regularly & $102 \pm 41.5$ & \\
\hline Car ownership & & \\
\hline Owners & 0 & \\
\hline Employed drivers & $246 \pm 100$ & \\
\hline Years of driving Car & $12.68 \pm 6.67$ & $3-28$ \\
\hline BMI (kg/m ${ }^{2}$ ) & $21.86 \pm 3.32$ & $15.53-30.31$ \\
\hline
\end{tabular}

${ }^{\mathrm{a}}$ Values denote mean $\pm \mathrm{SD}$, ${ }^{\mathrm{b}}$ Range: minimum and maximum value.

\section{Discussion}

This study examined the prevalence of LBP among car drivers of Dhaka city and it was found that $78 \%$ of taxi driver reported LBP during past 12 months which lasted for more than a day. Various epidemiological studies of professional car drivers in other countries reported prevalence range of LBP from 40 to $51 \%{ }^{2,4,12,14}$ In this cross-sectional study, the prevalence of LBW in car drivers of Dhaka city is found to be higher than the range reported LBP in previously published studies of professional car drivers. A study conducted among Taiwanese urban car drivers found the LBP prevalence of $51 \%\left(96 \%\right.$ of whom were men). ${ }^{2}$ Another study ${ }^{2}$ reported $57 \%$ of truck drivers (21-40 years of age) in Dhaka city of Bangladesh complained of LBP; the prevalence is much higher than the present study.

We found in our study that driving more than 7 hour/ day (8-16 hour/day) increase the risk by about 4 times than those who drive 1-7 hour/day. The Musculoskeletal Pain (MSP) is associated with driving duration conforms to the Taiwanese study, ${ }^{2}$ demonstrated that driving more than 4 hour/day was related to back pain $(95 \%$ CI 1.02-3.10). We had no additional information about other factors outside their driving work that might be associated with MSP. Those who do not drive much may have acquired back pain from previous exposure and therefore choose not to drive more, which relates to 
Table 2: Summarized results of crude analysis and binary logistic regression

\begin{tabular}{|c|c|c|c|c|}
\hline \multirow{2}{*}{$\begin{aligned} \text { Factors } \\
\text { Driving hours per day }\end{aligned}$} & \multirow[t]{2}{*}{ Respondents } & & \multirow[t]{2}{*}{$p$ value } \\
\hline & & \multicolumn{2}{|c|}{ OR $(95 \% \mathrm{CI})$} & \\
\hline $1-7$ hours & 146 & 1.0 & & \\
\hline $8-16$ hours & 100 & 3.934 & $(1.26-12.237)$ & $0.018^{*}$ \\
\hline \multicolumn{5}{|c|}{ Baggage handling index } \\
\hline Never-sometimes & 44 & 1.0 & & \\
\hline Frequent & 162 & 0.77 & $(0.31-1.92)$ & 0.576 \\
\hline \multicolumn{5}{|c|}{ Sleeping breaks in the car } \\
\hline Never & 56 & 1.0 & \multirow[b]{2}{*}{$(0.61-4.2)$} & \\
\hline Sometimes & 190 & 1.6 & & 0.336 \\
\hline \multicolumn{5}{|l|}{ Smoking index } \\
\hline Never/sometimes & 108 & 1.0 & & \\
\hline Frequent/ Regular & 138 & 0.847 & $(0.36-2.02)$ & 0.71 \\
\hline \multicolumn{5}{|l|}{ BMI } \\
\hline $15-23.99\left(\mathrm{~kg} / \mathrm{m}^{2}\right)$ & 186 & 1.0 & $(0.78-4.61)$ & \\
\hline $24-32\left(\mathrm{~kg} / \mathrm{m}^{2}\right)$ & 60 & 5.15 & $1.14-23.2$ & $0.033^{*}$ \\
\hline \multicolumn{5}{|l|}{ Years of driving Car } \\
\hline $2-8$ years & 84 & 1.0 & \multirow[b]{2}{*}{$(1.12-7.59)$} & \\
\hline $9-16$ years & 100 & 2.92 & & $0.028 *$ \\
\hline $16+$ years & 64 & 9.60 & $(2.01-45.82)$ & $0.005^{*}$ \\
\hline \multicolumn{5}{|l|}{ Age } \\
\hline 25-39 years & 124 & 1.0 & & \\
\hline $40-65$ years & 122 & 4.67 & $(1.74-12.68)$ & $0.002 *$ \\
\hline
\end{tabular}

Keys: BMI: Body mass index, OR: odds ratio, CI: confidence interval; *Values are significant $p<0.05$.

the general limitations of cross-sectional design in making casual inferences that must be kept in mind.

Contrary to previous findings ${ }^{4-6}$, more frequent baggage handling was not a risk factor for MSP in the present study. This may be explained by limitations to the questionnaire utilized as being too crude an indicator to be able to measure the actual amount of carrying, pulling and pushing. The present study also demonstrated that sleeping in the car seat during rest breaks was not a risk factor for LBP. Krause et al. ${ }^{5}$ identified "poor access to rest rooms on the line was a risk factor for back or neck pain among bus drivers. But the reason why this study did not find any relationship between LBP and rest breaks may be that drivers didn't want to disclose the fact that they take rest breaks inside the car. Contrary to results reported in other studies, ${ }^{1,6,7}$ smoking was not related to LBP in the present study. As supported by a number of previous studies, ${ }^{1,6,7}$ the present study also identified a higher BMI as a potential risk factor for MSP. Years of driving and age is also found to be positively correlated with LBP. But this result is not very significant as for elderly people there could be many other reasons which cause LBP. Pietri et al. ${ }^{14}$ reported that LBP was significantly related with time spent driving a car at work, comfort of the car seat, carrying loads during work, standing for long periods at work, smoking, and psychosomatic factors. A previous study conducted in Dhaka city among truck drivers found a statistically significant association between musculoskeletal problems and duration of truck driving, tons of truck, exposure to vibration, applied muscular effort, smoking habit, age of the truck driving, marital status and family size $(\mathrm{p}<0.05){ }^{3}$

The study has a number of limitations. This crosssectional study involved only car drivers of Dhaka city and had a small sample size; therefore, caution needs to be taken to generalize the findings. Pain is a motivation for responding in this study and it is possible that those who responded may exaggerate their pain in severity or duration. Moreover, as this is a cross-sectional study, associations have been established among variables but not the casual inferences.

\section{Conclusion}

We conclude that a high level of LBP (78\%) among car drivers of Dhaka city is present and that is associated with long working hours, BMI, and years of driving. Occupational health and safety management programs should be implemented to prevent adverse health effects in car drivers. In particular, a shortening of the driving time (e.g. a maximum of 7 hour/day) and introduction of appropriate resting areas should be considered. Further longitudinal studies can be done in other parts of Bangladesh to assess the severity and complex causation of LBP among car, lorry, bus and other drivers.

\section{References}

1. Brage S, Bjerkdal T. Musculoskeletal pain and smoking in Norway. J Epidemiol Community Health 1996;50:166-9. 
2. Chen JC, Chan WP, Chang WP, Christiani DC. Occupational factors associated with low back pain in urban taxi drivers. Occup Med 2005;55:535-40.

3. Khali MI, Rahman MM, Yasmin N, Ahsan GU, Faruquee MH. Musculoskeletal Problems among Truck Drivers in Selected Areas of Dhaka City. SUB J Public Health 2009; 2:22-8.

4. Funakoshi M, Tamura A, Taoda K, Tsujimura H, Nishiyama K. Risk factors for low back pain among taxi drivers in Japan. Sangyo Eiseigaku Zasshi. 2003;45:235-47.

5. Krause N, Ragland DR, Greiner B, Syme L, Fisher JM. Psychosocial job factors associated with back and neck pain in public transit operators. Scand J Work Environ Health 1997;23:179-86.

6. Leino-Arjas P, Hanninen K, Puska P. Socioeconomic variation in back and joint pain in Finland. Eur J Epidemiol 1998; 14:79-87.

7. Skov T, Borg V, Ørhede E. Psychosocial and physical risk factors for musculoskeletal disorders of the neck, shoulders, and lower back in salespeople. Occup Environ Med 1996;53:351-6.

8. Xu Y, Bach E, Orhede E. Work environment and low back pain: the influence of occupational activities. Occup Environ Med 1997;54:741-5.

9. Miranda H, Viikari-Juntura E, Punnett L, Riihimaki H. Occupational loading, health behavior and sleep disturbance as predictors of low-back pain. Scand J Work Environ Health 2008;34:411 -19 .
10. Lotters F, Burdorf A, Kuiper J, Miedema H. Model for the work-relatedness of low-back pain. Scand J Work Environ Health 2003;29:431 -40 .

11. Gheldof EL, Vinck J, Vlaeyen JW, Hidding A, Crombez G. The differential role of pain, work characteristics and pain-related fear in explaining back pain and sick leave in occupational settings. Pain 2005;113:71-81.

12. Porter JM, Gyi DE. The prevalence of musculoskeletal troubles among car drivers. Occup Med (Lond) 2002;52:4-12.

13. Nagasu M, Sakai K, Ito A, Tomita S, Temmyo Y, Ueno M, Miyagi S. Prevalence and risk factors for low back pain among professional cooks working in school lunch services. BMC Public Health 2007;7:171.

14. Pietri F, Leclerc A, Boitel L, Chastang JF, Morcet JF, Blondet M. Low-back pain in commercial travelers. Scand J Work Environ Health 1992;18:52-8.

15. Hoogendoorn WE, van Poppel MN, Bongers PM, Koes BW, Bouter LM. Systematic review of psychosocial factors at work and private life as risk factors for back pain. Spine 2000; 25: 211425.

16. Linton SJ. A review of psychological risk factors in back and neck pain. Spine 2000; 25: 1148-56.

17. Open Epi - Epidemiologic Calculators. http:// w w w. openepi.com/OE2.3/M enu/ OpenEpiMenu.htm (accessed June 2012) 